\title{
How are Small and Medium Enterprises in Malaysia's Furniture Industry Coping with COVID-19 Pandemic? Early Evidences from a Survey and Recommendations for Policymakers
}

\author{
Jegatheswaran Ratnasingam, ${ }^{\mathrm{a}, *}$ Albert Khoo, ${ }^{\mathrm{b}}$ Natkuncaran Jegathesan,,${ }^{\mathrm{c}, *}$ \\ Lum Chee Wei, ${ }^{\mathrm{d}}$ Hazirah Ab Latib, ${ }^{\mathrm{a}}$ Ganesh Thanasegaran, ${ }^{\mathrm{e}}$ Lim Choon Liat, ${ }^{\mathrm{a}}$ \\ Lee Yan Yi, ${ }^{a}$ Kamaruzaman Othman, ${ }^{f}$ and Mohd. Afthar Amir ${ }^{f}$
}

\begin{abstract}
In the wake of the global COVID-19 pandemic and the subsequent movement control order (MCO) in Malaysia, an on-line survey was undertaken involving 748 small and medium enterprises (SMEs) in the furniture industry. The main objective was to examine the impact of the pandemic and the subsequent MCO on the various business aspects of the SMEs as well as to make recommendations to the government on supportive measures for the SMEs. The survey found that although all aspects of the business were impacted, the two major concerns of the SMEs during this crisis were the financial management and the supply chain disruptions. Inevitably, it was found that most of the SMEs were operating well below capacity, which was a huge financial strain on their business viability. It was recommended that the government provide measures to help the SMEs manage their cash-flow and ease the restrictions to facilitate supply-chain commencement that is crucial to their business. The survey also revealed that most SMEs acknowledged the importance of automation and the adoption of technologies. Respondents regarded the shift towards Industry 4.0 was inevitable as a means increase their resilience when facing future uncertainties.
\end{abstract}

Keywords: COVID-19 pandemic; Furniture; SMEs; Finance; Supply-chain; Automation

Contact information: a: Faculty of Forestry, Universiti Putra Malaysia, 43400 UPM, Serdang, Selangor, Malaysia; b: Malaysian Furniture Council (MFC), Lot 19A, $19^{\text {th }}$ Floor, Menara PGRM, 8, Jalan Pudu Ulu, Cheras, 56100 Kuala Lumpur, Malaysia; c: Faculty of Business, University of Wollongong, NSW 2522, Australia; d: Muar Furniture Association (MFA), No. 38, Wisma MFA, Jalan Bakri, 84000 Muar, Johor, Malaysia; e: Faculty of Business Administration, Universiti Putra Malaysia, 43400 Serdang, Selangor, Malaysia; f: Malaysian Timber Industry Board (MTIB), Level 13-17, Menara PGRM, Jalan Pudu Ulu, 56100 Kuala Lumpur, Malaysia;

*Corresponding authors: jegaratnasingam@yahoo.com; j.natkuncaran@gmail.com

\section{INTRODUCTION}

The Malaysian furniture industry has become a success story of industrial development from the perspective of many countries around the world. From its humble beginning in the early 1980s, as a cottage-based industry, offering a small number of products for the domestic market, it has been transformed into a multi-billion ringgit export power-house within a period of three decades (Malaysian Timber Industry Board (MTIB) 2019). Ranked amongst the top 10 largest exporters of furniture in the world, Malaysia exports around $85 \%$ of its total production to countries such as the United States of America (USA), Japan, United Kingdom, Europe, Singapore, India, Australia, and even the Middle 
East. It has been reported that Malaysian furniture is being exported to 116 countries throughout the world, and the developed economies account for almost $70 \%$ of the export volume (MIFF 2018).

The growth of the Malaysian furniture industry, especially its wooden furniture sector that accounts for almost $83 \%$ of its total production, can be attributed to a unique combination of pull and push factors (Ratnasingam 2015). The emergence of rubberwood (Hevea brasiliensis) as an important wood resource for furniture manufacturing in the early 1980s, after a decade-long research program by the Forest Research Institute of Malaysia (FRIM) was among the important pull factors, in addition to the availability of a cheap workforce, especially from the rural areas. Coincidently, the disruption in the furniture supply-chain from the previous Balkan state of Yugoslavia to the USA created a vacuum in the market that was capitalized by furniture manufacturers in the country. The presence of the large multinational furniture manufacturers, especially from Taiwan and South Korea, also assisted the rapid expansion in production capacity to serve the export markets (Ratnasingam 2015). In contrast, the important push factor was the implementation of a series of Industrial Master Plans (IPMs), i.e., $1^{\text {st }}$ IMP (1986 to 1995), $2^{\text {nd }}$ IMP (1996 to 2005), $3^{\text {rd }}$ IMP (2006 to 2020), and the National Timber Industry Plan (NATIP) helped transform the industry into a furniture and other value-added wood products manufacturing hub in the region, through provision of business-friendly policy, regulatory, and fiscal instruments (MTIB 2019). In fact, the transformation of the furniture industry in Malaysia into a manufacturing power-house has become the envy of many countries throughout the world, and its growth model has become an example to be emulated, and has been well researched (Ratnasingam 2017).

In 2019, the total furniture export from Malaysia amounted to RM 11.38 billion, with wooden furniture making up $83 \%$ of this total (MTIB 2020). While providing employment to almost 105,000 people, the furniture industry also has a strong presence in the domestic market valued at RM 8.9 billion, with a spill-over effect of another RM 7.5 billion in terms of indirect and supporting activities. In this context, the Malaysian furniture industry is an important socio-economic sector that has gained prominence over the years.

Wooden furniture manufacturing has predominated the furniture manufacturing industry since the early 1980s, and it accounts for almost $85 \%$ of annual furniture production. Although other types of furniture, such as bamboo, rattan, metal, leather, and wood-panels are gaining importance, the unsustainable supply of these materials as well as its cost disadvantage when compared to wooden furniture, puts much restraint on the manufacture of these types of furniture (Ratnasingam 2017; MTIB 2019). The emergence of China and Vietnam, as the top two largest producers and exporters of furniture in the Asian region, has also put a dent on Malaysia's hope of gaining a stronghold in the other types of furniture. As it stands, Malaysia is now ranked $3^{\text {rd }}$ in the league of furniture producers and exporters in Asia, with China and Vietnam holding firm to the number one and number two positions (MTIB 2019).

Despite the growing regional competitive pressure, the Malaysian wooden furniture industry has remained resilient and its export performance as well as it domestic sales have remained strong (Fig. 1). 


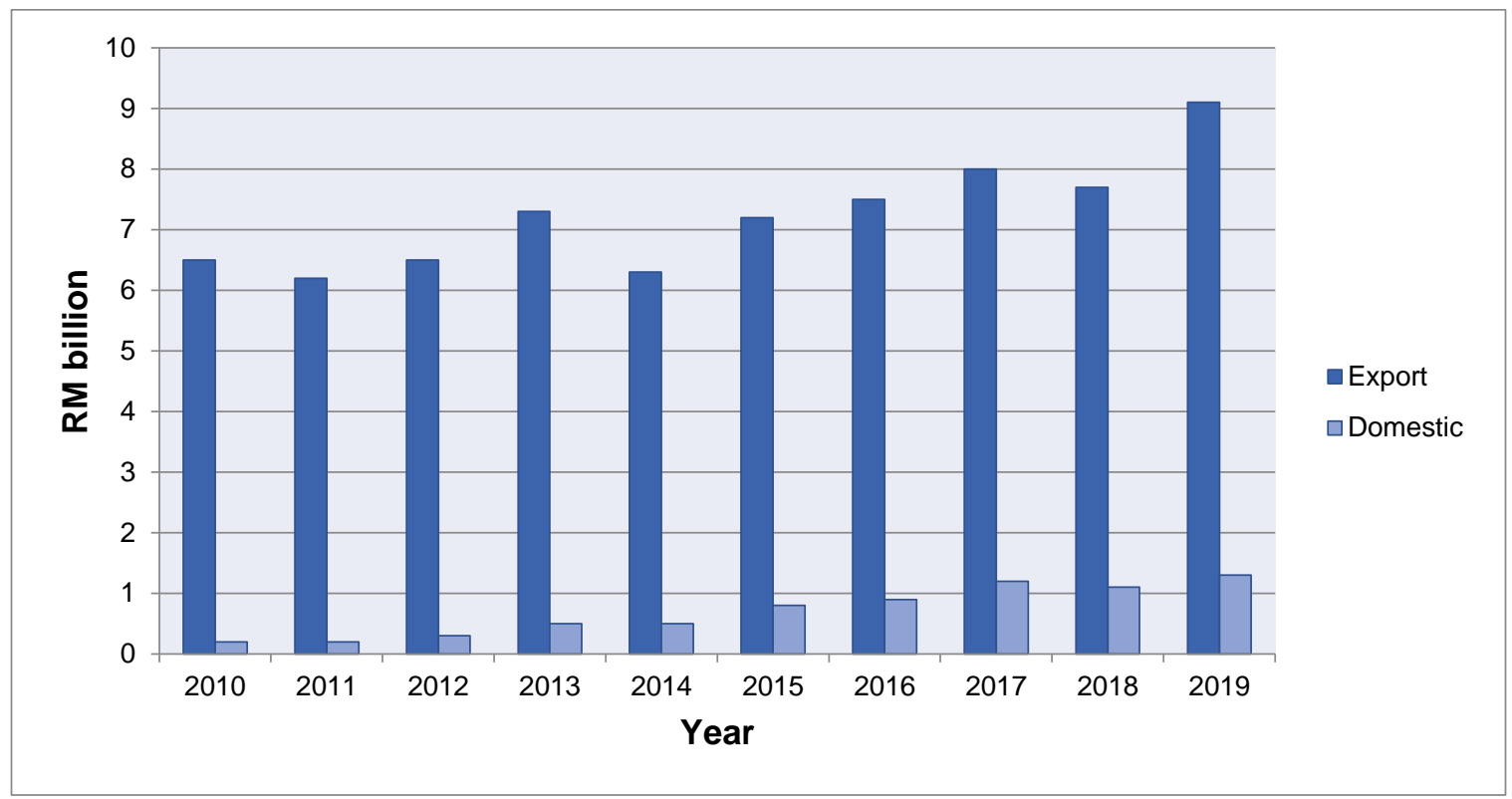

Fig. 1. Malaysia: Export and domestic sales of wooden furniture, 2010 to 2019 (Source: MTIB 2020)

\section{The Importance of SMEs in the Malaysian Furniture Industry}

Furniture manufacturing is the fastest growing sub-sector within the country's wood-based industry, and accounts for approximately $1.1 \%$ of the total gross domestic product (GDP) of Malaysia (Ratnasingam 2017). The furniture industry is predominated by small and medium enterprises (SMEs), which make up almost $85 \%$ of all registered furniture manufacturing enterprises in the country. For the manufacturing sector, SMEs are defined as firms with sales turnover not exceeding RM 50 million, or with the number of full-time employees not exceeding 200.

The MSMEs make up almost $93 \%$ of all registered business entities in the country and within the manufacturing sector. SMEs account for almost $86 \%$ of all registered establishments. In this context, the SMEs being the backbone of the manufacturing sector in the country plays a huge role in ensuring the viability of the whole sector (MIDA 2019). Any impact on the performance of the SMEs, due to external or internal factors, may significantly affect the performance of the manufacturing sector. According to the SME Corp. (2019), the furniture industry has the largest number of SMEs compared to any other manufacturing sector, and this was attributed to the cottage-based beginnings of the industry, which was developed by local entrepreneurs to cater for domestic needs. This was particularly true of the Muar furniture cluster, which was fueled by the rapid growth of small sub-contracting operations catering for the huge demand of several Taiwanese multinationals operating in the vicinity. For instance, the total number of furniture manufacturing establishments in Muar in the early 1980s were reported to be 17, while in 2016 this number had grown to almost 845 (Ratnasingam 2017). Figure 2 shows the industrial structure of the furniture manufacturing industry in the country. 


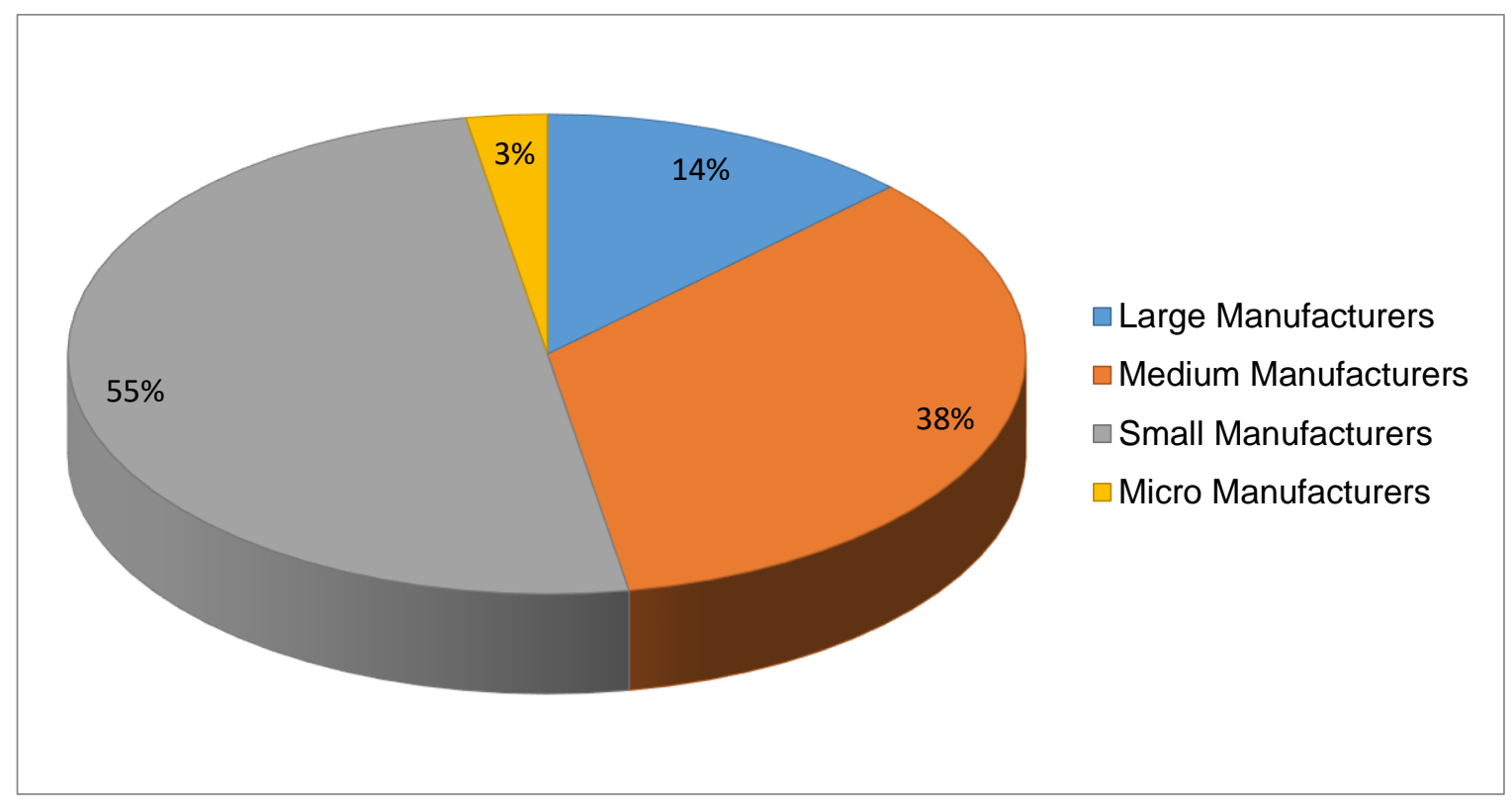

Fig. 2. Proportion of SMEs in the furniture sector (MTIB 2019)

The furniture industry in Malaysia has several well-developed industrial clusters, operating in several regions, such as Muar, Batu Pahat, Melaka, Sungei Buloh, Taiping, Kuantan, and Sungei Petani, located across the length of the country. These industrial clusters are well organized and self-sustaining, in the sense that apart from manufacturing furniture, the supporting industries, such as tooling, finishing, fittings, shipping, logistics, etc., are all operating within the vicinity, which allows for just-in-time delivery. Apart from that, there are a large number of sub-contractors, specializing in specialty components, who are able to provide the much needed design diversity as well as volume production (Ratnasingam 2017). Such industrial clusters, which have a well-developed and complex supply chain, are indeed the strength of the Malaysian furniture industry.

Categorically, SMEs in the furniture industry rely on the speed of their operation and the quick delivery of their goods. Hence, cash-flow and supply chain management are the two most important aspects that govern the viability of the SMEs in the furniture sector. In an earlier study led by Ratnasingam and McNulty (2016), it was shown that most SMEs in the country were affected greatly by the financial and market disruptions, in case of an economic downturn. The 2008/2009 economic crisis brought many SMEs in the furniture industry in Malaysia to their knees, as many faced closures and bankruptcy, due to cancellation of orders, non-payment for goods delivered, and inventory build-up. The study also highlighted that almost $65 \%$ of the $1^{\text {st }}$ generation SMEs in the furniture industry did not survive this down-turn, and the non-performing loans (NPLs) of many of these companies had to be wiped-off the books of many commercial banks, hence, rendering the sector the tag of being a high financial risk manufacturing sector. Inevitably such a sector also suffered from a high potential to lay-off workers, when the demand for furniture was reduced significantly. In a study on furniture retailers operating in Malaysia by Ratnasingam and Kumaravel (2017), it was shown that when a recession sets in, furniture purchases are among the first activities to be sacrificed, as they are non-essential purchases. Further, when the disposable income becomes reduced, furniture purchases also suffer. Therefore, furniture demand is predetermined not only by the strength of the housing start- 
ups, construction activity, disposable incomes among the populace, demographics, and other related factors that influences the furniture purchase decision.

In a report by the Malaysian Furniture Council (2018), it was shown that the furniture industry, particularly the SMEs, contributes a significant amount towards the government coffers. For instance, furniture companies' income taxes, domestic sales tax, permits, licenses, etc. account for almost RM 1.6 billion per annum, which makes the furniture industry an important commercially viable sector in the country's economic pie. As an important player in the country's fashion sector, with a huge potential to shift towards greater value-addition and brand identification, the sustained growth of the furniture industry is an important economic agenda in Malaysia (MIDA 2019).

\section{COVID-19 and the Movement Control Order (MCO) in Malaysia}

The novel corona virus infectious disease (COVID-19) was declared a global pandemic by the World Health Organization (WHO) on 11 March 2020. The COVID-19 epidemic, which started explosively in Wuhan, China in late 2019, turned into a pandemic within two months, mediated through the massive global aviation industry (WHO 2020). The virus is of zoonotic origin and is primarily transmitted from symptomatic people to others who are in close contact through respiratory droplets, by direct contact with infected persons, or by contact with contaminated objects and surfaces (Shailendra 2020). The COVID-19 shows somewhat similar symptoms as the severe acute respiratory syndrome (SARS), also first reported in China more than a decade ago. As of April 4, 2020, the number of cases climbed above 1 million with a death toll of over 50,000 worldwide. The global impact and the public health threat of COVID-19 is the most serious seen in a respiratory virus, since the 1918 influenza pandemic. Both COVID-19 and the 1918 influenza pandemic are associated with respiratory spread, where a significant percentage of infected people with asymptomatic cases transmitting infection to others, coupled with a high fatality rate (WHO 2020).

In Malaysia, the COVID-19 has been critically evaluated by the government, in accordance with a set of guidelines by the WHO, which are to be followed to prevent a massive spread. As of April 25, 2020, there were 5,742 cases and 98 deaths in Malaysia (Ministry of Health (MOH) 2020). In lieu of these developments, the Malaysian government has been taking prompt public health actions to prevent an exponential rise of COVID-19 cases by continuously screening and testing high-risk individuals, isolating patients, and tracing and quarantining the contacts to prevent secondary spread and community-based transmission ( $\mathrm{MOH} 2020)$. Inevitably, social-distancing has become the norm in all daily activities.

In the dire urgency to control the outbreak, while preventing the collapse of the over-stretched healthcare system, the government was forced to impose a more stringent action. A limited lock-down in the form of a series of MCO has been implemented since 18 March 2020 by the government. The $1^{\text {st }} \mathrm{MCO}$, followed by the $2^{\text {nd }} \mathrm{MCO}$, and at the time of this writing the $3^{\text {rd }}$ MCO, until 12 May 2020 has shut down all non-essential sectors, including wood products manufacturing (MIDA 2020). The implementation of the MCO is not without a cost to society. It has major social and economic disruptions, coupled with increased anxiety among the society at large about the length of the MCOs and also its socio-economic and psychological repercussions (Ratnasingam 2020). The possible effects of the COVID-19 pandemic on the global economy has been well documented in Baldwin and Weder (2020) and International Labor Organization (ILO) (2020). The Organization for Economic Cooperation and Development's (OECD) policy response towards the SMEs 
(OECD 2020) is also another noteworthy publication on this subject, but focus on SMEs in the wood products and furniture industry has been negligible. In fact, it was suggested by Ratnasingam (2020) that against a global threat of a recession, the trade war between the USA and China as well as other impending geo-political challenges, SMEs in many countries will be severely impacted. To question of the impact of the COVID-19 and the subsequent MCOs on the SMEs in the furniture industry warrants special attention, because in an unfortunate event of a non-recovery of the SMEs, the future growth of the furniture industry in Malaysia may be severely affected.

Therefore, a study was undertaken to examine the effects of the COVID-19 global pandemic and the subsequent MCOs on the SMEs in the furniture industry, and also provide recommendations on possible support measures from the government to enable the SMEs to cope with the MCOs, while being able to resume operations when the MCOs are eventually lifted. This study is particularly important considering the fact that the sustainability of the Malaysian furniture industry is dependent on the strength of its SMEs.

\section{METHODOLOGY}

Due to the urgency of the study, an on-line survey of furniture manufacturers, especially SMEs, was carried out with the assistance of the Malaysian Furniture Council (MFC) and the respective state associations. Although such a method enables quick responses to be obtained at lower cost, real-time, increased response rate, automated data input and provide flexibility in design, on its flip side it may have compromised its accuracy due to possibility of survey fraud, lack of interviewer, and the difficulty in getting the right respondent or limited sampling (Liu et al. 2020). The first part of questionnaire was designed to capture the effects of the COVID-19 global pandemic and the implementation of the MCOs on the important activities of furniture SMEs, including (1) raw materials supply, (2) workforce, (3) production, (4) supply chain, (5) financial management, (6) market demand, and (7) logistics. Each activity encompassed eight identifiable effects, which the respondents had to rank from a scale of 10 (highly relevant) to 1 (not relevant at all), depending on the effect the MCOs had on it. The questions were focused on assessing the impact the MCOs had on these essential activities of the SMEs. The second part of the questionnaire required the respondents to list down the five most important support mechanisms expected of the government to assist the furniture SMEs during this period and also suggest measures that could be implemented to become more resilient and sustainable to cope with future uncertainties.

The questionnaire was designed and implemented using Google Forms (Google LLC, Mountain View, CA, USA) after consulting several industry experts, and the data were captured and compiled after two weeks of launching the survey. The Malaysian Furniture Council assisted in ensuring 784 respondents (i.e., 41\% representation) were obtained from a total of 1890 registered furniture SMEs.

The compiled data of responses were analyzed, and the averages were presented graphically. The top five significant effects from each activity were also presented graphically. The student's T-test was used to ascertain the significance, which was set at the level of $\mathrm{P}<0.05$. The $\mathrm{P}$-value is the probability that the results from the data occurred by chance and reflects the probability of finding the results to show no significant differences between the factors tested (i.e. null hypothesis). It is calculated using the sampling distribution of the test statistic under the null hypothesis, the sample data, and the 
type of test being done. This was carried out using the Excel Spreadsheet of Microsoft Windows Professional Version 10 (Redmond, WA, USA).

\section{RESULTS AND DISCUSSION}

The results of this study were divided into two parts, i.e., Part I focused on the impact of COVID-19 pandemic and the subsequent implementation of the MCOs on the SMEs in the furniture industry, while Part II discussed the recommendations to policymakers to support the SMEs during this period and the possible measures that could be taken by the SMEs to improve their resilience and preparedness to face another uncertainty in the future.

\section{Part I: Effect of COVID-19 Pandemic and the MCOs on the SMEs}

Based on the responses from the survey, it was apparent that raw materials supply for the SMEs negatively was affected during this period. The primary concerns highlighted were uncertain supply, inconsistent price, and inconsistent quality (Fig. 3). This was due to the fact that sawmilling, wood treatment, and wood drying activities were affected during this period, because without any planned replanting activities, the supply of rubber saw-logs from the plantations to the sawmill was uncertain. This is particularly crucial because rubberwood is the main feedstock for the wooden furniture manufacturing industry in Malaysia (Rubber Industry Smallholders Development Authority (RISDA) 2018).

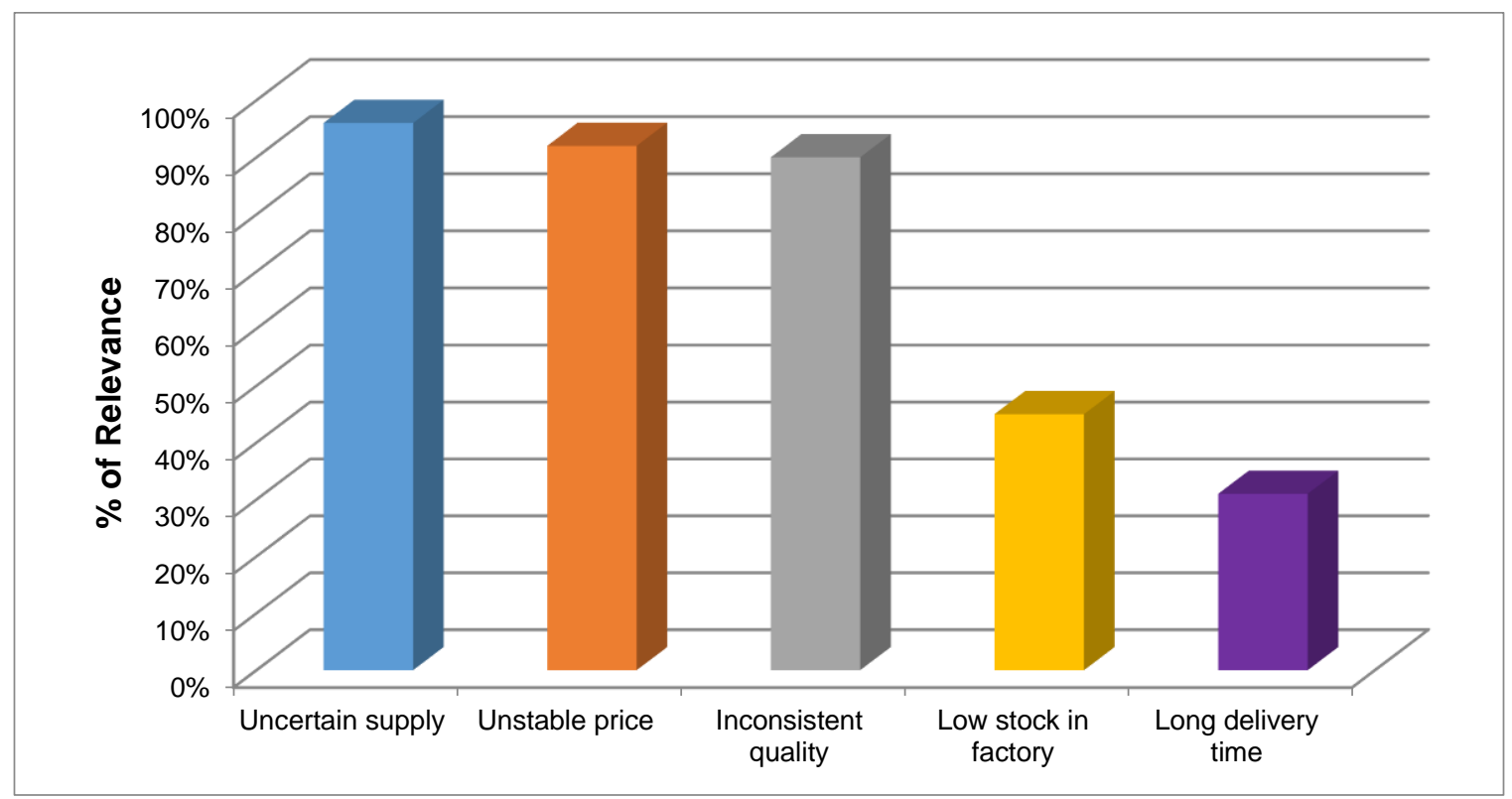

Fig. 3. Impact on raw materials supply

In terms of the workforce, the primary concerns for SMEs were refusal to work, absenteeism, and low labor productivity of the workforce. Figure 4 reveals the impacts due to workforce on the SMEs during this period. In fact, the SMEs in the furniture industry were helpless, because many of the workers employed are foreign contract workers, and therefore contractual obligations may make their employment during the MCOs less productive and costly (Ratnasingam 2015). 


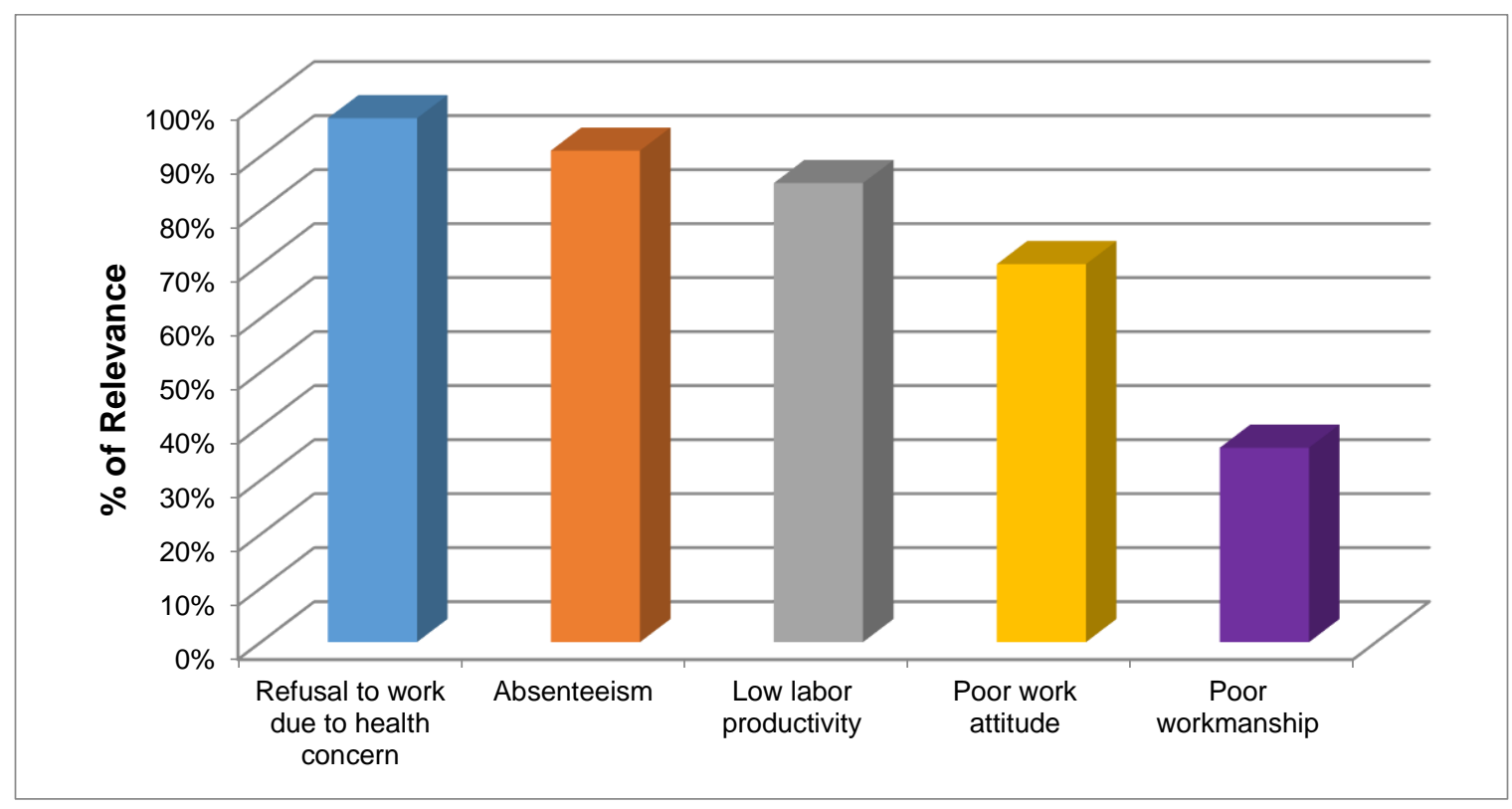

Fig. 4. Impact on workforce

In terms of production, the biggest concern among SMEs was the underutilized production capacity, followed by the low level of work-in-progress (WIP) and sub-standard workmanship (Fig. 5). The disruption in raw materials supply explained this observation among the SMEs.

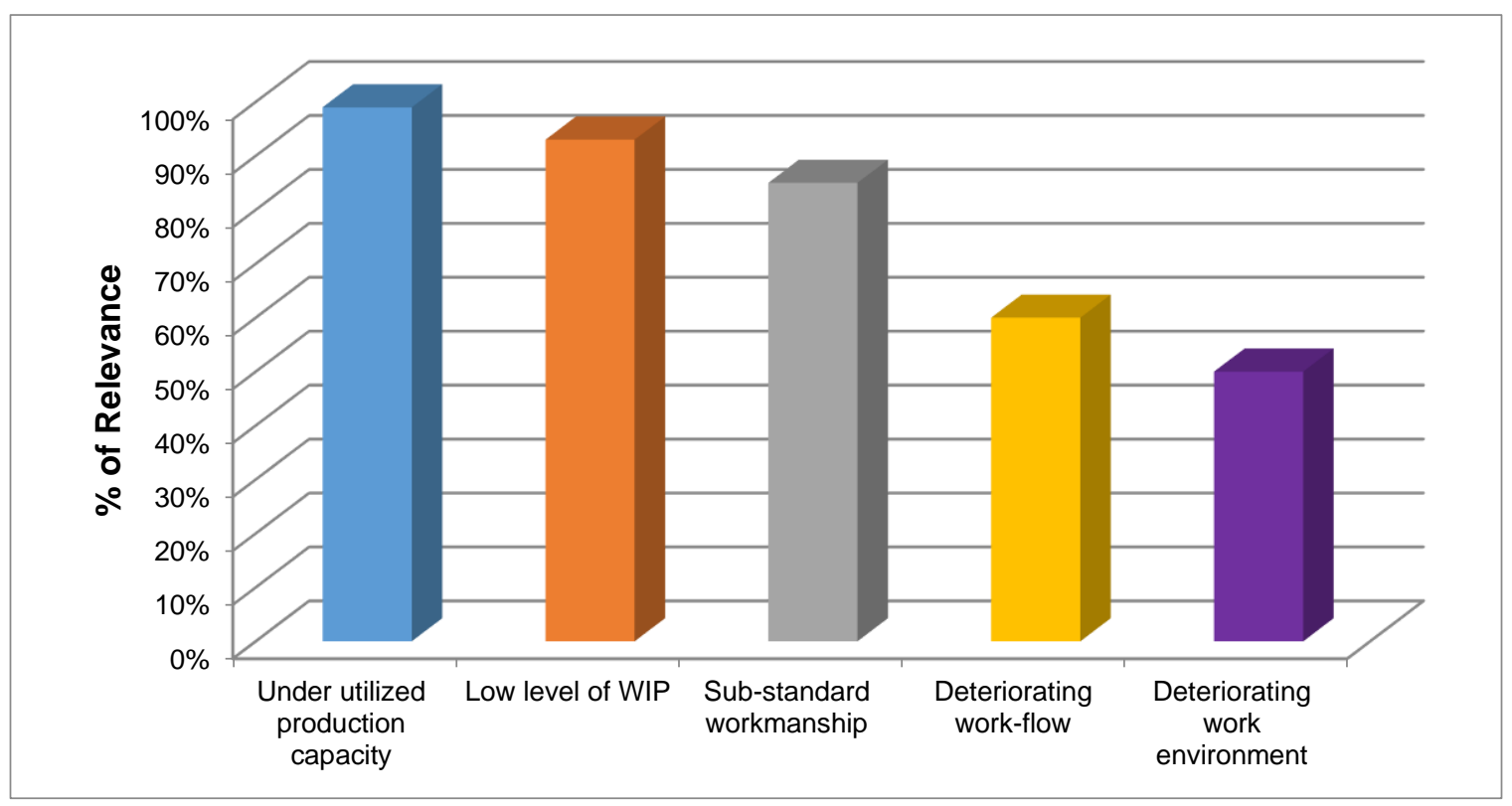

Fig. 5. Impact on production

The impact on the supply-chain was perhaps of paramount importance to the SMEs. Among the key issues faced are lack of supporting industries (i.e., finishing, fittings, tolling supplies, etc.), lack of supporting services (i.e., component suppliers, finishing services, 
drying services, carpentry, proto-typing, etc.), and too long delivery times (Fig. 6). It has been reported that the impact on the supply-chain for SMEs would be most severe in resource-based industries due to the disruptions in materials supply (OECD 2020), especially during crises as elucidated by Baldwin and Weder (2020).

In the case of the Malaysian furniture industry, the SMEs are the backbone of the industry clusters, and any disruptions in the supply chain will have a far reaching impact on the whole furniture manufacturing cluster. Personal communications with some of the SMEs in the Muar furniture cluster indicated that for every day of non-operation, a loss of RM 58 million was incurred among the 640 manufacturers within the cluster. Therefore, the aspect of supply-chain and its recovery after the MCOs will determine if the furniture industry is able to rebound after this crisis.

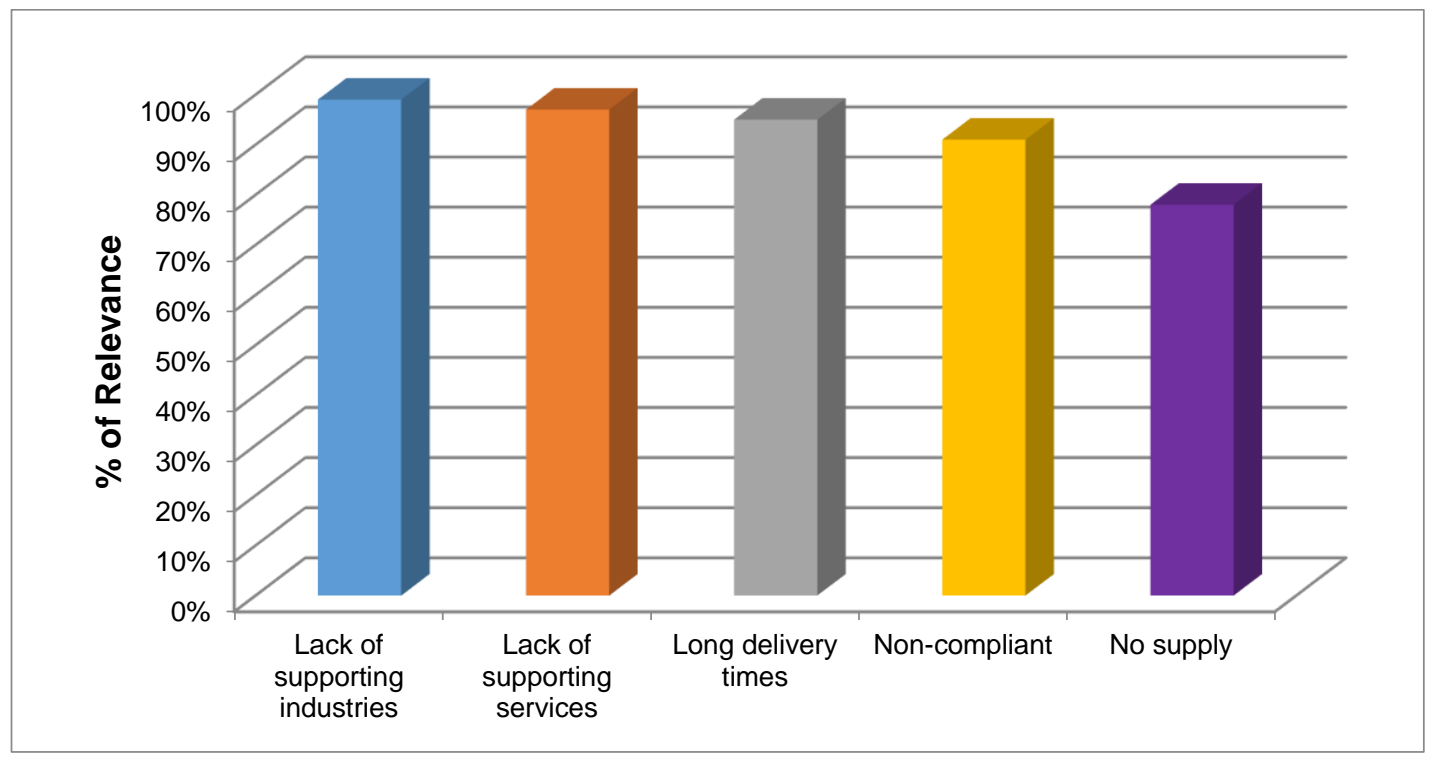

Fig. 6. Impact on supply chain

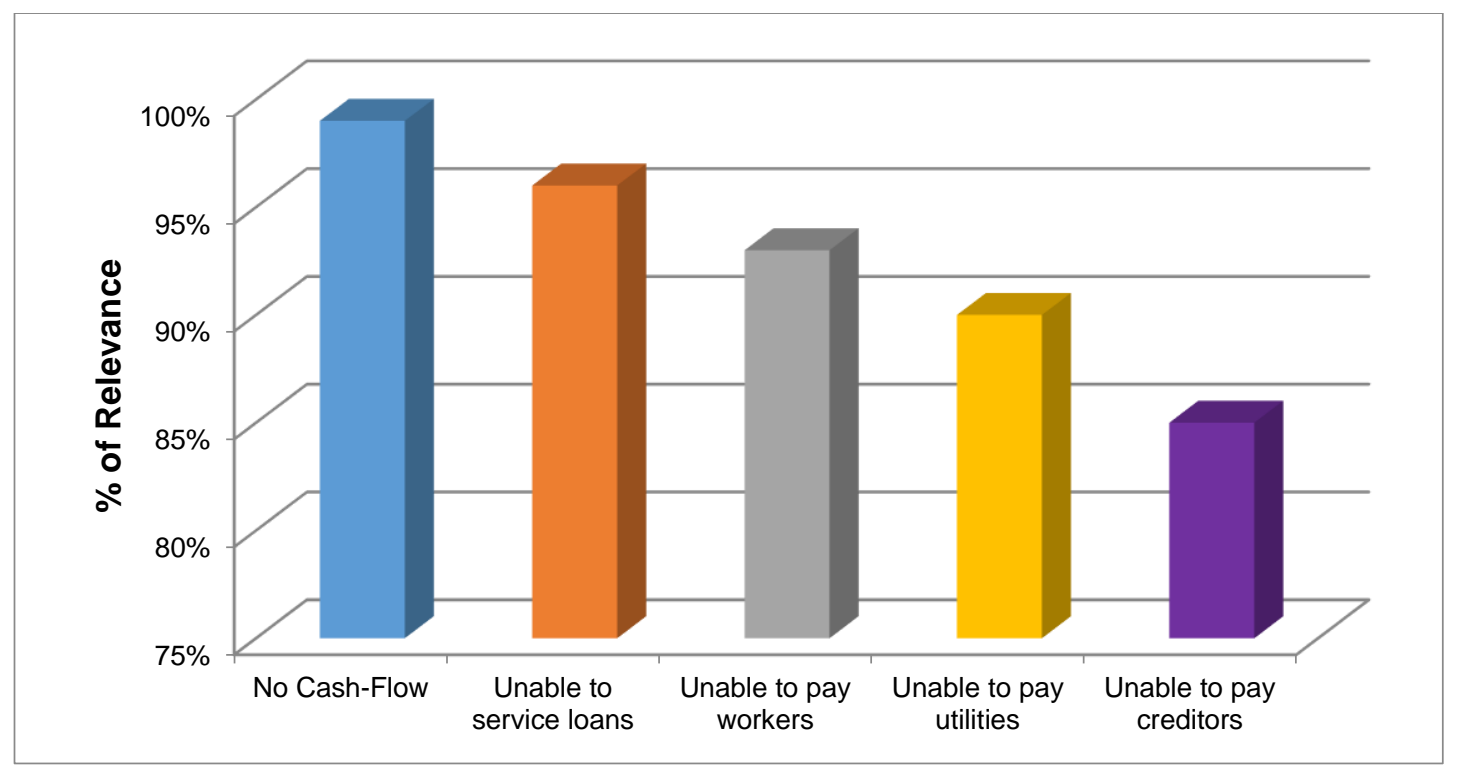

Fig. 7. Impact on financial management 
The impact on the financial management of SMEs is shown in Fig. 7. As expected, the cash-flow, servicing of loans/borrowings, and inability to pay workers have been highlighted as the primary concerns. Because most SMEs are operating on a tight working capital, without cash-flow from a continuous economic activity, their financial management is adversely affected (OECD 2020). The employment of foreign workers, governed by their contractual obligations, makes it difficult to lay them off, and hence, being non-productive during this period is also costly (ILO 2020). In some instances, the inability to transact and receive payments from overseas is also negatively impacting the financial status of the SMEs.

Even before the emergence of the COVID-19 pandemic, the export market for furniture in the USA and Europe has been sluggish. As result, furniture export activities in Malaysia has also been slow, and it was envisaged that after the annual trade fairs in March, business should pick up (MTIB 2019). Unfortunately, the COVID-19 pandemic and the subsequent MCOs, have ended any hopes of such a turn of events. Although many SMEs claimed to have the ability to shift towards domestic market sales, in reality the MCOs have shrunk the domestic retail market for furniture significantly in the country during this period (MIFF 2020). Although E-commerce is being promoted aggressively, the net effect appears to be negligible, as furniture purchase often requires viewing and touching of the physical product (Ratnasingam 2015). Figure 8 reveals the important impacts on the furniture market during this period.

It is known that almost all major international furniture shows, in High Point (USA), Milan (Italy), Malaysian International Furniture Fair (MIFF) (Kuala Lumpur), Export Furniture Exhibition (EFE) (Kuala Lumpur), China International Furniture Fair (CIFF) (Guangzhou, China), and others have been postponed due to the COVID-19 pandemic. Inevitably, this has resulted in loss of potential sales for the year as well as new product launches for the year. According to MIFF (2020), the loss in marketing opportunity is severe as these fairs contribute immensely to the annual furniture export volumes for the respective countries.

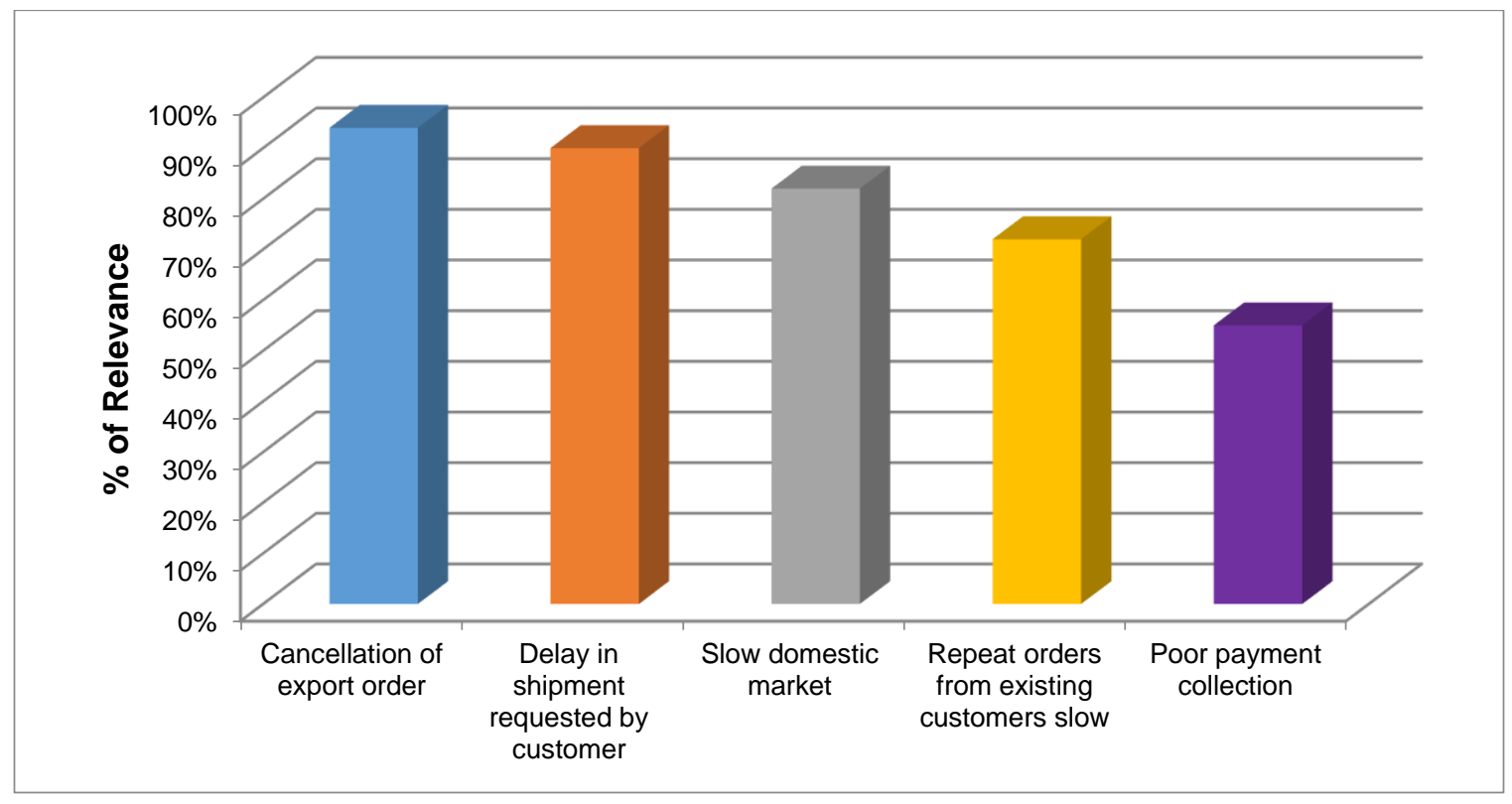

Fig. 8. Impact on market demand 
Logistics, which include domestic transportation, port services, and shipping, were also affected severely by the COVID-19 pandemic as well as the MCOs. The survey revealed that the SMEs are negatively influenced by the lack of logistics during this period (Fig. 9). During the MCO, poor transportation and the closure of port activities had a negative impact on export trade, as many furniture SMEs who struggled to ensure time delivery of shipments, were caught off-guard when no forwarding and shipping activities could take place. Hence, they had to bear additional demurrage cost and other taxes imposed by the port authority for storage space of their containers. In fact, according to Ratnasingam (2020), the increased cost due to poor logistics during the COVID-19 pandemic and MCOs to SMEs could be in the range of an additional 5\% of their overall manufacturing cost.

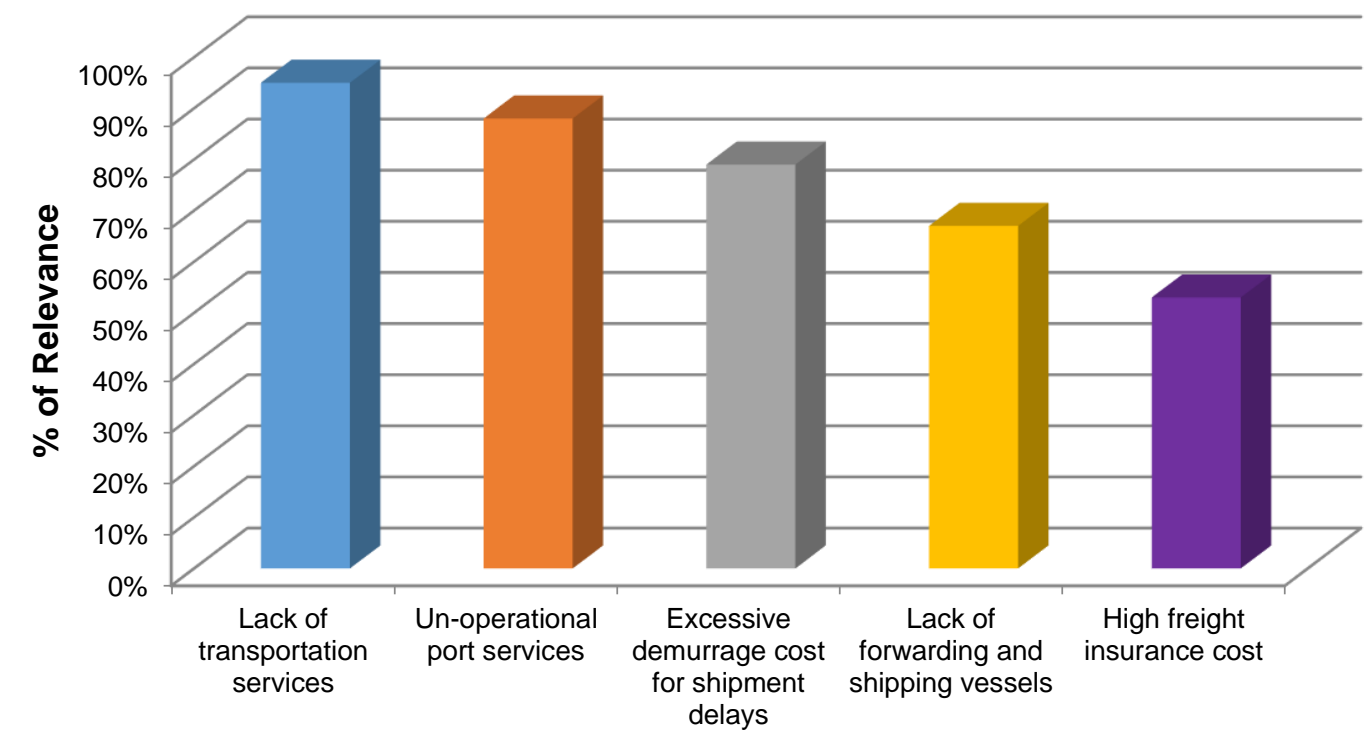

Fig. 9. Impact on logistics

\section{Part II: Recommendations to Policymakers to Supports SMEs and Possible Measures to Improve the Resilience of SMEs for Future Uncertainties}

The COVID-19 pandemic and the ensuing MCOs had severe impacts on the activities of the furniture SMEs in the country. Many of the respondents surveyed highlighted the needs for several supportive measures to be extended by the government to support the furniture and wood-based SMEs during the period. Among the important ones are:

1. The partial exemption of the MCOs for furniture SMEs will allow manufacturing operations to proceed at least up to $65 \%$ of the factory's capacity. This also will enable the factories to optimize their recurring costs.

2. The government should mandate all commercial banks to defer repayment of instalments for working capital loans and machinery loans for a period of 6 to 12 months for SMEs in the furniture industry. Rental and local government taxes should also be deferred for at least 6 months.

3. The government should provide a wage-subsidy to assist furniture manufacturers to offset their workers' wage cost during this period, when cash-flow was tight. In the 
case of employment of foreign workers, the government should provide an interestfree loan to SMEs to cover at least $50 \%$ of the minimum wage of their contract foreign workers, with the eventual plan to replace these workers with a local workforce.

4. The government should also ensure minimum disruption of the supply-chain for SMEs, as this will enable them to stay afloat during this crisis period. Hence, essential support services for the SMEs should be allowed to operate on a daily basis, even for a limited duration, during this period.

5. The government must also ensure that the SMEs are facilitated in their applications for support from the government, and not burdened by regulatory and other legislative requirements during this period.

The SMEs also highlighted that the COVID-19 pandemic and subsequent MCOs have revealed some weaknesses within the furniture clusters, especially among the SMEs. Almost all the respondents of the survey indicated that SMEs must seriously explore and adopt automation, information, and computer technologies (ICT) to ensure less reliance on workforce during periods of crisis. In fact, it may also be the best time for the government to provide automation subsidies and also push for an industry-wide adoption of Industry 4.0 technologies of the industry (ILO 2020). Further, digitalization and E-commerce have also emerged as essential tools to be adopted by the furniture industry, especially the SMEs, in relation to market development and expansion. It is also apparent that furniture product development during this period can only be handled virtually through the use of several Industry 4.0 technologies, which are already prevalent in the market. Under such circumstances, it is also apparent that future workforce for the furniture sector must be competent with ICT and Industry 4.0 technologies to be productive.

Unfortunately, the SMEs are also aware that the weaker and vulnerable members would go out of business (Elshenawi and Wang 2020), while the more efficient, forwardlooking SMEs would come back stronger in the near future. Perhaps, the COVID-19 pandemic and the subsequent MCOs is a period of industry consolidation, weeding out the inefficient manufacturers from the furniture industry. In this context, it may be advisable to carry out a follow-up survey when the MCOs is lifted and business resumes normality, to evaluate the extent of the impact of the COVID-19 pandemic and the MCOs on SMEs as well as the overall effect on the economy. This would provide an insight into the extent of economic damage the COVID-19 pandemic has had on the manufacturing industry as a whole. In addition, this possibly may provide insights to policymakers to prepare relevant intervention instruments to better cope with such crises in the future.

\section{CONCLUSIONS}

The preliminary survey of SMEs in the furniture industry in Malaysia during the COVID-19 pandemic and the subsequent MCOs revealed the following conclusions:

1. The SMEs in the furniture sector have been severely affected in terms of financial management and supply chain disruptions during this crisis. Inevitably, the ability to pay wages, utilities, service of borrowings, etc. were negatively impacted, if not lost completely.

2. The SMEs in the furniture sector are heavily dependent on traditional markets, such as the USA, Europe, Japan, and Singapore. Hence, there is an urgent to explore other 
markets, and provide market support for SMEs to expand their market base through the use of E-commerce and other digital platforms.

3. The SMEs also must be encouraged through the provision of subsidies and grant to adopt greater automation and high-end technologies to ensure their reliance on workforce is minimized.

4. The crisis has revealed that SMEs were impacted from all angles of the business, which must therefore be facilitated to increase their resilience, to cope with other future uncertainties.

\section{ACKNOWLEDGEMENTS}

The authors are grateful to the Malaysian Furniture Council (MFC) and Muar Furniture Association (MFA) for the assistance rendered during the implementation of this survey. The assistance of the SME Corp. of Malaysia in the design of the survey is also much appreciated. The authors are grateful for the financial support from Universiti Putra Malaysia under the PUTRA Grant No. 9649900, for the survey is acknowledged.

\section{REFERENCES CITED}

Baldwin, R., and Weder, B. (2020). Mitigating the Covid Economy Crisis - Act Fast and Do Whatever it Takes, CEPR Press, London, England.

Elshenawi, D. M. and Wang, Y. (2020). "How to protect factory workers from COVID19?" BioResources 15(4).

International Labour Organization (ILO) (2020). COVID-19 and the World of Work: Impact and Policy Responses, ILO Publication, Vienna, Austria.

Liu, K., Wang, H., Liu, H., Nie, S., Du, H., and Si, C. (2020). "COVID-19: Challenges and perspectives for the pulp and paper industry worldwide," BioResources 15(3), 4638-4641.

Malaysian Furniture Council (MFC) (2018). "Socioeconomic contributions of the Malaysian furniture sector," MFC Newsletter 1, 7-8.

Malaysian Furniture Council (MFC) (2019). "Trends in wood resources demand and supply for furniture industry," MFC Newsletter 4, 8-10.

Malaysian International Furniture Fair (MIFF) (2018). "The Malaysian furniture industry - A powerhouse in the making," MIFF Newsletter 4, 7-10.

Malaysian International Furniture Fair (MIFF) (2020). "E-Commerce as a furniture Marketing tool in ASEAN," MIFF Newsletter 3, 13-15.

Malaysian Investment Development Authority (2019) "Furniture manufacturing in Malaysia - A growth sector," MIDA Industry Brief 2, 14-15.

Malaysian Investment Development Authority (2020). "Impact of COVID-19 pandemic on the Malaysian economy - A preliminary assessment," MIDA Newsletter 2, 7-12.

Malaysian Timber Industry Board (MTIB) (2019). Annual Report of the Malaysian Wood Industry, MTIB, Kuala Lumpur, Malaysia.

Ministry of Health (2020). "Facing up to the COVID-19 pandemic - Flattening the curve, MOH Newsletter 1, 5-8. 
MTIB (2020). Annual Report of the Malaysian Wood Industry, MTIB, Kuala Lumpur, Malaysia.

Organization for Economic Cooperation and Development (2020). Tacking Covid-19SMEs Policy Response, OECD Publications, Paris, France.

Ratnasingam, J. (2015). The Malaysian Furniture Industry - Unravelling Its Growth and Challenges to Innovation, Universiti Putra Malaysia Press, Serdang, Selangor.

Ratnasingam, J. (2017). The Malaysian Furniture Industry: Charting Its Growth Potential. Inaugural Lecture Monograph No. 216, Universiti Putra Malaysia Press, Serdang, Malaysia.

Ratnasingam, J. (2020). Socioeconomic Impact of the COVID-19 Pandemic on the WoodBased Industry in Malaysia (IFRG Report. No. 6/SP), International Furniture Research Group, Singapore.

Ratnasingam, J., and Kumaravel, S. (2017). Shrinking Market for Furniture Exporters A Study of Major Retailers, SMU Press, Singapore.

Ratnasingam, J., and McNulty, T. (2016). An Evaluation of Supply Chain Management among SMEs in the Furniture Sector, ASEAN Trade Consultative Group Report, Bangkok, Thailand.

Rubber Industry Smallholders Development Authority (RISDA) (2018). Annual Report on the Rubber Sector in Malaysia, Rubber Industry Smallholders Development Authority, Kuala Lumpur, Malaysia.

Shailendra, K. S. (2020). Coronavirus Disease 2019 (COVID-19): Epidemiology, Pathogenesis, Diagnosis, and Therapeutics (Medical Virology: From Pathogenesis to Disease Control), Springer-Nature, Singapore.

SME Corporation Malaysia (2019). Status of the SMEs in the Manufacturing Sector (SME Corp. Publication No. 4/P), SME Corporation Malaysia, Kuala Lumpur, Malaysia

World Health Organization (2020). The Novel Coronavirus (COVID-19): Emergence, Spread and Control (WHO Brief No. 8), WHO, Geneva, Switzerland.

Article submitted: April 29, 2020; Peer review completed: June 10, 2020; Revised version received and accepted: June 11, 2020; Published: June 16, 2020.

DOI: $10.15376 /$ biores. 15.3.5951-5964 